\title{
Developing and Stabilizing Salt-Hydrate Composites as Thermal Storage Materials
}

\author{
Gayaneh Issayan \\ Energy Systems ASiC \\ University of Applied Sciences Upper \\ Austria \\ Wels, Austria \\ Gayaneh.Issayan@fh-wels.at
}

\author{
Bernhard Zettl \\ Energy Systems ASiC \\ University of Applied Sciences Upper \\ Austria \\ Wels, Austria \\ Bernhard.Zettl@fh-wels.at
}

\author{
Walter Somitsch \\ Consultant Engineer \\ Vienna, Austria
}

\begin{abstract}
The success of thermochemical storage technologies is currently defined by sorptive materials. High adsorption heat and kinetics are material properties, which should correspond to application demands, such as utilizable temperature range and cyclability. Following the example of zeolite production in robust granular form, composite materials were developed which incorporate salt-hydrates in porous host structures. This work presents a new concept of composite material development, wherein hygroscopic salts calcium and lithium chloride are stabilized in clinoptilolite and vermiculite structures, using a granulation process. Additional focus was put on low primary energy input for production steps and taking into account parameters for large-scale production of the composites. Various binder substances and methods were studied. The mechanical stability and adsorption/hydration behavior of salt-composites were investigated. The search for processing approach and alternative binder materials showed promising results.
\end{abstract}

Keywords - thermochemical storage, salt-hydrate, composite materials, granulation, adsorption

\section{INTRODUCTION}

Harvesting and storing solar energy for a year-round supply of renewable heat in domestic buildings paves the way to low carbon energy targets. Thermal energy storages (TES) are the solution of compensating the seasonal mismatch in demand and supply of solar energy and fully tap its potential in the heating energy sector. TES can be classified in three main branches based on the storing mechanisms: sensible (e.g. water tank with $250 \mathrm{MJ} / \mathrm{m}^{3}$ energy density), latent (e.g. inorganic phase change materials $300-500 \mathrm{MJ} / \mathrm{m}^{3}$ ), and thermochemical heat storages (e.g. synthetic zeolites and salthydrates $\left.0.7-2.8 \mathrm{GJ} / \mathrm{m}^{3}\right)[1]$. The first two branches are represented by commercial products in the market in contrast to thermochemical storages, which are yet to be adequately developed and demonstrated. Sorption processes are based on the ability of certain materials, sorbents, to interact or bind other molecules in their structure, called sorbates. The reaction is reversible and exothermic, here referred to as discharging. The product of the reaction can be separated into the reactants by application of heat representing the charging process. Sorption reactions themselves are divided into liquid absorption and solid sorption, which serves for both reversible physical solid adsorption and/or chemical reaction [2]. Various working pairs of sorbents and sorbate fluids were studied based on adsorption heat, energy density, regeneration temperature, environmental impact, etc. [3-5]. Alongside

This work was founded within New-TCM (Wi-2018-97351-/9-RA) project by the EU-European Regional Development Fund (ERDF) and Federal Province of Upper Austria- Investments in Growth and Jobs (IGJ). costly tailored materials as metal-organic frameworks- MOFs [6], (silica) aluminophosphates - SAPOs and AlPOs [7][8], most prominent and well-studied adsorbents are silica gels [9], zeolite molecular sieves [10][11], and various hygroscopic salts [3]. Whereas the latter ones currently attract attention due to their ability to store heat without noticeable losses during the dehydration process and extracting heat when introduced to humidity. Thermochemical storage materials stand out by exceptionally high theoretical energy densities (0.7$2.8 \mathrm{GJ} / \mathrm{m}^{3}$ ) [1][12]. A broad range of salt-hydrates have been screened and demonstrated alongside desired sorption attributes, challenging and instable handling mainly due to their hygroscopic behavior (deliquescence) and damages in crystal structure during/after de-/rehydration cycling [13]. Common salt-hydrates used in sorptive applications are $\mathrm{MgSO}_{4}, \mathrm{MgCl}, \mathrm{CaCl}_{2}, \mathrm{LiCl}, \mathrm{SrBr}_{2}, \mathrm{Na}_{2} \mathrm{~S}$ and $\mathrm{LiBr}$ [2]. The use of pure salt-hydrates without structural support in porous frameworks, utilized as thermochemical materials (TCM), was shown to result in low stability under hydrothermal manipulations [13].

On the one hand, synthetic zeolites display mechanical and cycling stability, but on the other hand, they are deficient due to their high regeneration temperatures, cost- and energyintensive production. The efforts to combine the advantages of sorptive materials in sophisticated composites led to various methods, i.e. wet impregnation of salts in several porous structures [14][9][15], wet incipient impregnation by incorporation of salts during synthesis [16], or encapsulation of salts by polymers [17]. Regardless of refined material design and enhanced adsorption, these methods/materials are either not appropriate for applicable operating conditions or foresee rather high production costs, making them commercially unattractive [12]. Since the named materials were not able to fulfill the criteria regarding adsorption properties, application compatibility, primary energy demand, and cost at once, alternatives had to be found. This research aims to develop low-cost, eco-friendly seasonal TES composites demonstrating the potential for mass production, and reports on the advancements.

In this work, we attempted to stabilize the salt-hydrates via different well-accessible porous structures, binders, and coating mechanisms. Therefore, an existing demonstration of thermochemical storage reported in [18] was considered, defining the crucial material requirements. The storage is based on an open sorption system, where humidity from ambient air serves as sorbate. The sorptive material was stored 
in a cylindrical rotating drum reactor (moving bed). The latter one was proven to optimize vapor mass transport through the material by a homogenous distribution of the vapor and preventing the formation of a distinct reaction front. The open storage system was dimensioned, simulated, and tested with 4A zeolite material. The key requirement for a successful application of the end-product proofed to be the mechanical stability of the granules. The production route of spherical granular zeolite also served as inspiration for determining applicable processing steps for the production of composite alternatives. The choice of raw materials was conducted considering cost aspects while maintaining favorable sorption properties and beneficial environmental impact.

\section{MATERIALS AND METHODS}

\section{A. Materials}

\section{1) Salt hydrates}

The broad price-range of hygroscopic salts or salthydrates, such as calcium chloride $\left(\mathrm{CaCl}_{2}\right)$, is governed by the availability, quality, and purity of the compounds. Due to the desire for the big-scale production of the composites, the economic factor was more than convincing in the case of calcium chloride. Besides, highly hygroscopic salt $\mathrm{CaCl}_{2}$ stands out due to its beneficial hydrothermal properties: it absorbs water vapor at ambient conditions (room temperature and relative humidity), and it's dehydration already begins from $150^{\circ} \mathrm{C}$, which is convenient for solar thermal applications [19][20]. The named advantages benefited the utilization of $\mathrm{CaCl}_{2}$ in thermochemical composites, mostly in combination with various pore-sized host structures [21-23]. The composites were prepared with $\mathrm{CaCl}_{2}$ dihydrate, which is one of the stable hydrates. Four solid hydrates are identified in the literature, where the highest hydration phase is the hexahydrate, exhibiting high thermal conductivity [24][20]. Lithium chloride was also studied as a single salt, as well as in composites [25][26]. The deliquescence relative humidity of $\mathrm{LiCl}$ is higher than that of $\mathrm{CaCl}_{2}$ [27]. Previous research has shown in the case of using/mixing both salts, the deliquescence of $\mathrm{CaCl}_{2}$ was raised, which is favorable for the stability of the salt-hydrate ${ }^{1}$. The composites produced for this work contained $70 \mathrm{wt} . \% \mathrm{CaCl}_{2}$ and $30 \mathrm{wt} . \% \mathrm{LiCl}$. The named composition revealed the highest water uptake values in former investigations of salt impregnated samples. ${ }^{2}$

\section{2) Porous hosts}

The energy demand for the production of synthetic zeolites is rather high and can be avoided by the use of natural zeolites, e.g. over $7 \mathrm{MWh} /$ ton of A-type zeolite $v s$. approximately $0.13 \mathrm{MWh} /$ ton of clinoptilolite. The latter one is a natural clay (mineral) with a regional occurrence and is commonly used in agriculture. The mineral originates from sedimentary volcanic deposits (tuff). Earlier investigations concerning salt impregnation of natural clinoptilolite grains $(\mathrm{d}=1-2.5 \mathrm{~mm}) \mathrm{did}$ not yield adequate results. Water uptake measurements performed on the host material in grain form saturate around 5-6 wt.\%. Clinoptilolite used in the preparation of current composites was provided in particle sizes of $\mathrm{d}(90)<70 \mu \mathrm{m}$, and $35 \mathrm{~m}^{2} / \mathrm{g}$ BET surface ${ }^{3}$. The chemical composition is

\footnotetext{
${ }^{1}$ Project TES4SET (FFG 845020), final report, 2019.

${ }^{2} \mathrm{CaCl}_{2}$ : Soda Polska Ciech, Inowrocław, Poland. LiCl: Leverton-Clarke, Basingstoke, UK.
}

[w/w \%]: $\mathrm{SiO}_{2}: 69.6 ; \mathrm{Al}_{2} \mathrm{O}_{3}: 12.0 ; \mathrm{MgO}: 0.9 ; \mathrm{K}_{2} \mathrm{O}: 3.0 ; \mathrm{CaO}$ : 2.8; $\mathrm{Na}_{2} \mathrm{O}: 1.1 ; \mathrm{Fe}_{2} \mathrm{O}_{3}: 1.6 ; \mathrm{Si} / \mathrm{Al}$ ratio: 5.1. This product features a high percentage of calcium and potassium and slight amounts of sodium and magnesium. In addition to clinoptilolite, natural clays as vermiculite, which belong to the family of layer silicates, were also considered.

\section{3) Binders}

Despite the low weight percentages (5-20 wt.\%), binders play an important role in providing pores for vapor transport and mechanical strength by building a coherent framework. Inorganic mineral phyllosilicates (clay) as attapulgite, montmorillonite, and kaolinite are commonly used in zeolite granulation. Hence, a commercially distributed attapulgite was selected. Attapulgite covers the zeolite powder grains during the mixing and granulation process and establishes a needle-like structure network holding the zeolite grains after activation by thermal treatment (calcination). The latter procedure is described thoroughly in section $\mathrm{C}$.

Alternatives for low cost and widely available binders can be acquired in construction industries, i.e. inorganic minerals, which also harden by crystallization phenomena. In construction engineering, binders are categorized based on their ability to harden in air only or air and water, nonhydraulic and hydraulic, respectively. The hydraulic binders are considered water-resistant after a certain curing period, making them attractive for hygroscopic salt-composites. The most prominent one of hydraulic binders is Portland (limestone) cement, which is mostly used to stabilize rocky aggregates to concrete.

The theoretical background regarding Portland cement and various additives for this work was gathered from [28].The distinct reaction of cement hydration is the formation of calcium silicate hydrate $\mathrm{C}-\mathrm{S}-\mathrm{H}$ phase. Basic calcium oxide or lime (burnt) reacts with water to form alkaline calcium hydroxide, evoking a reaction with the acidic silicates (fly ash, quartz, etc.) and resulting silicic acid $\mathrm{H}_{4} \mathrm{SiO}_{4}$. Subsequently (several) water-resistant and cross-linked calcium silicate hydrates crystallize out with the following general Equation (1):

$$
\mathrm{xCa}(\mathrm{OH})_{2}+\mathrm{ySiO}_{2}+\mathrm{zH}_{2} \mathrm{O} \rightarrow
$$

$\mathrm{xCaO} \mathrm{ySiO}_{2}(\mathrm{x}+\mathrm{z}) \mathrm{H}_{2} \mathrm{O}$. (1)

Limestone, clay or a natural mixture of both like lime marl serve as raw materials for clinker production. Depending on the quality of the natural resources, further iron ore and quartz sand are added to the mixture. After milling, the mixture is sintered up to $1450^{\circ} \mathrm{C}$, rapidly cooled afterward, and milled again. Four different clinker phases are formed during and through sintering, which is responsible for the hydraulic characteristics of the cement end-product. The phases are tricalcium silicate $\mathrm{C} 3 \mathrm{~S}$ - alit, di-calcium silicate $\mathrm{C} 2 \mathrm{~S}$-belit, tricalcium aluminate $\mathrm{C} 3 \mathrm{~A}$, calcium alumina-ferrite $\mathrm{C} 2(\mathrm{~A}, \mathrm{~F})$. The phases and corresponding concentrations define the properties of the cement regarding curing and setting behavior, hydration heat, etc. Next to clinker, various additives in normed concentrations are adapted in cement production, i.e. furnace slag, natural and/or synthetic

\footnotetext{
${ }^{3}$ Clinoptilolite: IPUS GmbH, Rottenmann, Austria
} 
pozzolans, fly ash, silica dust, etc. Each influencing the resulting material properties. Alkali sulfates should also be considered for modifying multiple phases of the curing process. In absence of sulfate additives, calcium aluminate hydrate $\mathrm{Ca}_{4} \mathrm{AlH}_{13}$ will form spoon-like bridges immediately, which would prevent further processing. Otherwise, with sulfate additives in the clinker mixture the crystallization of calcium aluminate hydrate sulfate, known as ettringite, occurs in trigonal structures. The elongated needle-like crystals enveloping C3A grains slow the hydraulic reaction. Ettringite crystallization would dominate the early curing stages (AFtphase) as described in Equation (2). This phase can be controlled by adding gypsum (anhydrite).

$$
\begin{aligned}
& 3 \mathrm{CaO} \mathrm{Al} \mathrm{O}_{3}+3\left(\mathrm{CaSO}_{4} 2 \mathrm{H}_{2} \mathrm{O}\right)+26 \mathrm{H}_{2} \mathrm{O} \rightarrow \\
& 3 \mathrm{CaO} \mathrm{Al}_{2} \mathrm{O}_{3} 3 \mathrm{CaSO}_{4} 32 \mathrm{H}_{2} \mathrm{O}
\end{aligned}
$$

Pozzolanic reactions should also be mentioned in this context, as they are crucial for a systematic variation of the utilized cement types. Pozzolans are silica-based materials that lack hydraulic properties but engage in reactions in the presence of silicic acid building calcium silicate hydrate C-S$\mathrm{H}$ presented in Equation (3). The latter is bearing the mechanical stability of the end-product.

$$
\mathrm{Ca}(\mathrm{OH})_{2}+\mathrm{H}_{4} \mathrm{SiO}_{4} \rightarrow \mathrm{CaH}_{2} \mathrm{SiO}_{4} 2 \mathrm{H}_{2} \mathrm{O}
$$

Alongside different additives, the concept of expanding cement should also be addressed. The time and volume of the expansion are controlled by balancing the curing time and formation of ettringite. The speed of ettringite formation increases proportionally to the mole ratios of $\mathrm{CaO}$ and $\mathrm{Al}_{2} \mathrm{O}_{3}$ and does not depend on Ca-sulfate components. The ratio of $\mathrm{Ca}$-aluminates and $\mathrm{Ca}$-sulfates, on the other hand, influences the expansion extent.

Hydraulic binders, such as cement, present new opportunities as well as certain challenges. The cement hydration reactions are highly alkaline and chlorides produce acidic solutions when dissolved. In the case of chloride salts, overhydrating and development of solutions (hydrolysis), will cause $\mathrm{Ca}(\mathrm{OH})_{2}$ to gradually dissolve, which disturbs or hinders the curing (formation of stable C-S-H phases) of the cement matrix. This fact should also be considered in further processing steps and testing procedures of the salt-hydrate composites. The mechanical stability gain in common cement applications is achieved by increasing the density and decreasing the porosity, which is not compatible with the concepts of sorptive materials.

Samples were prepared with the following cement mixtures and named accordingly. [Binder-type]:

- Portland cement - PC

- Cement with natural pozzolan additives - PZ

- Cement with sulfate additives - PS

\section{B. Granulation Method}

Granulation procedures are widely used in diverse branches of industrial processing, i.e. spray, drum, and disc granulation. The latter approach was selected due to its flexibility regarding processed materials, as well as the simplicity and low energy consumption of the procedure. Insights about the main granulation parameters, the ability to manipulate the material, and to observe the development during the procedure directly were noted as advantages of this approach. The disc granulator displayed in Figure 1 was used in a laboratory setting to produce granules in $1-2 \mathrm{~kg}$ total material amounts. The rotational speed, which was coupled with the motor power of the disc, the tilting angle, and the amount of water were modified depending on the material properties. Further batches of $10 \mathrm{~kg}$ were produced in available industrial-scale granulators.

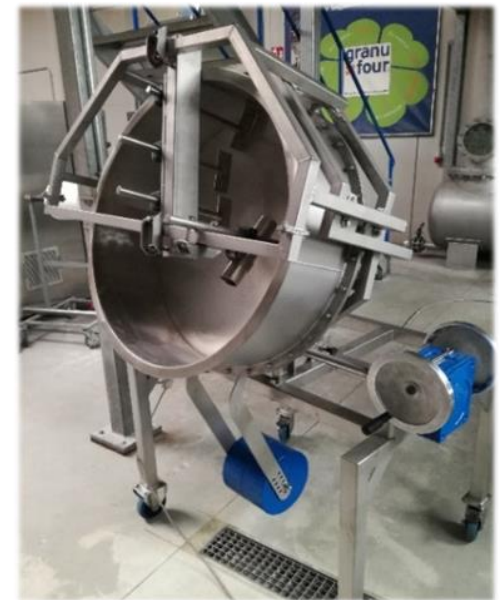

Figure 1 Laboratory scale granulation disc utilized for 1-2 kg material batches.

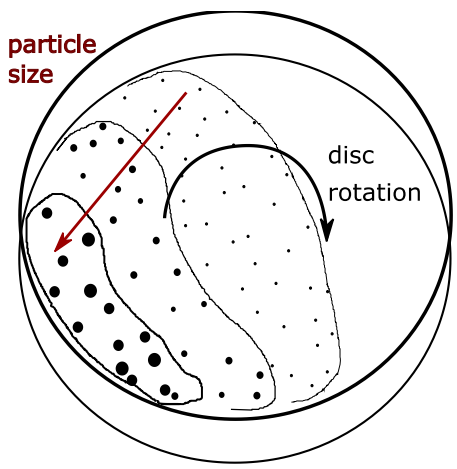

Figure 2 Disc granulation: from powder to granules. Initial material: light humid powder would roll and build small agglomerates, which then increase in diameter, gain weight, and move to the disc's edge as , as indicated by the red arrow.

The operation mode for disc granulation is sketched in Figure 2. The raw materials were first milled to fine homogenous powders and mixed by high-speed compulsory mixers. During the procedure, a specified amount of water was added to the mass to prepare it for the granulation. The material, or a portion of it, was then placed into the (moving) disc. The moist material evolved small spherical agglomerates and by growing in volume, the granules rolled towards the disc's edge, where they were cast out as indicated in Figure 2. The granulation was controlled and optimized by additional moisture, sprayed during the process. The remains of the initial raw-material mixture were then subsequently added to the disc for continual processing. The granules were then sieved to multiple desired ranges and dried at appropriate temperatures.

\section{Calcination}

A pressing issue regarding attapulgite bound granules was the study of thermal treatment, here referred to as calcination, of the samples. The calcination parameters highly influence 
the thermal and mechanical stability of the samples. Outgassing (or activation: water of crystallization < 1 wt. \%) as $\mathrm{NaX}$-granules, are achieved at $350-400^{\circ} \mathrm{C}$, whereas the attapulgite binder in $\mathrm{NaX}$ requires higher calcination temperatures about $500^{\circ} \mathrm{C}$ for guaranteed mechanical stability of the granules [29]. To ensure the hydrothermal stability of zeolite structures, gentle thermal treatment is facilitated by low heating rates and constant removal of the water vapor by flushing gas. To develop similar thermal processing for saltcomposite granules, hydrothermal properties of each component contained in the samples had to be considered and investigated.

The research in the zeolite field concluded that the $\mathrm{Si} / \mathrm{Al}$ ratio influences the thermal stability of zeolites: ratios greater than 3.8 are considered thermally stable and unstable below 1.2. The structural water release occurs at temperatures of $140-400^{\circ} \mathrm{C}[30]$ and collapsing to amorphous structures arises at temperatures of about $1000^{\circ} \mathrm{C}$ [31]. A maximum volume contraction of $3.6 \%$ was found at $300^{\circ} \mathrm{C}$. Chandrasekhar et al. reported an intact crystalline structure of $\mathrm{CaA}$ and $\mathrm{CaX}$ zeolites synthesized from kaolinite and calcined up to $750^{\circ} \mathrm{C}$. The samples calcined with heating rates of $1^{\circ} \mathrm{C} / \mathrm{min}$ resulted in porous, unstable products, and those with $3^{\circ} \mathrm{C} / \mathrm{min}$ resulted in compact, stable products, respectively [32]. In the case of natural clinoptilolite, sintering temperatures in the range of $900-1100^{\circ} \mathrm{C}$ were reported [33]. In our previous research on calcination of salt-clinoptilolite composites in the presence of different binders at $550^{\circ} \mathrm{C}$ for 4 hours did not increase the mechanical stability of the granules. Further adsorption measurements confirmed the structural degradation of the composites indicating a decline of water vapor adsorption. Hence, sintering effects were anticipated for zeolites which were calcined at even higher temperatures.

Attapulgite structure can be described as $\mathrm{Si}-\mathrm{O}-\mathrm{Si}$ bound layers (T-O-T ribbons) along fiber axes with tunnel-like nanopores (parallel to the fibers) [34]. Kuang et al. examined the thermal behavior of attapulgite and observed four stages of water-loss: for temperatures up until $130^{\circ} \mathrm{C}$ lightly bound pore water was discharged. The structural water was released in two further steps, first between $130-270^{\circ} \mathrm{C}$ and second between $270-580^{\circ} \mathrm{C}$. The last step of water loss in $580-950^{\circ} \mathrm{C}$ range followed, which is called dihydroxylation [34]. The crystal structure of attapulgite folds and collapses above $350^{\circ} \mathrm{C}$, when structural water molecules are released and the layers approach each other tightly, which results in further binding of $\mathrm{Mg}$ with $\mathrm{O}$ of neighboring layers. The process is irreversible above this temperature and the density (sintering) of the bonds increases, whereas the porosity of the tunnels decreases with the temperature [34].

Besides calcination and sintering effects, the melting temperature of $\mathrm{CaCl}_{2}$ and $\mathrm{LiCl}$, which correspond to $772^{\circ} \mathrm{C}$ and $614^{\circ} \mathrm{C}$, had to be considered. The chloride salts tend to release hydrogen chloride $\mathrm{HCl}$ (gas) during certain stages of thermal treatment. In a dry atmosphere, gaseous $\mathrm{CaCl}_{2}$ reacts with oxygen in the air, which results in chlorine gas $\mathrm{Cl}_{2}$. Whereas in humid conditions, chloride salt reacts with the water in the air resulting in $\mathrm{HCl}$. The latter scenarios take place above $782^{\circ} \mathrm{C}$ [24]. In the case of $\mathrm{LiCl}$, the reaction with water results in $\mathrm{LiOH}$ and $\mathrm{HCl}$ through hydrolysis at temperatures above $800^{\circ} \mathrm{C}$ [35].
As the preparation methodology of the composites is unique and not yet studied to a satisfactory extend, verifying the calcination approach had to be tested. Therefore, composite samples were calcined at temperatures between $350-750^{\circ} \mathrm{C}$ for $0.5-3.0$ hours with a heating rate of $2 \mathrm{C} / \mathrm{min}$. Possible losses in adsorption properties due to sintering at high temperatures were thereby expected. However, further improvement of the mechanical stability of the granules due to sintering was anticipated.

\section{Mechanical stability measurements}

This work aims to produce thermochemical materials for seasonal storage applications to endure a minimum of 20-30 cycles (years) of loading/unloading in hardship case of assumed moving drum reactors. These factors dictate the necessity for high granular mechanical stability, which can further be maintained during multiple cycles and variations of humidity and temperature. Hence, the break resistance was the first essential attribute to be tested after an initial visual check of color, form, and size of the products. The granules of each batch were tested by applying a vertical force on them and registering the peak force values at the first breaking point as depicted in Figure 3. The latter setup was developed emulating the principle of compression tests at a constant velocity, whereas the force was applied manually and the velocity was only controlled by the elastic resilience of a spring recoiling the piston.

The sample size of the examined batches was kept constant at 25 granules for each measurement and was further reproduced. The samples were analyzed at varying ambient relative humidity for specified temperatures.

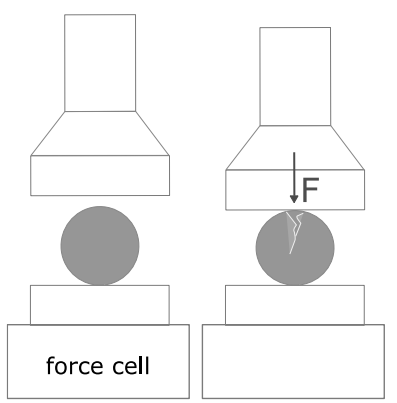

Figure 3 Break resistance testing setup: vertical force $\mathrm{F}$ is applied to the granules and the first peak force is registered.

\section{E. Adsorption / hydration characterization}

The adsorption/hydration behavior of the samples was investigated with the help of the "characteristic curve" concept according to Dubinin, which is a consequence of Polanyi's theory of adsorption [36]. The adsorbed water volume at equilibrium stages as a function of Gibbs (free) energy is the final consequence of this theory and the visualization is known as the characteristic curve. This concept can be better understood by Equation (4). The latter represents the adsorption potential (or affinity) $\Delta \mathrm{F}$ of a sorbent to bind adsorptive molecules on the porous matrix sites by transforming the vapor to condensed water. Whereas $\mathrm{R}$ is the gas constant, $\mathrm{T}_{\text {sorb }}$ is the sorbent temperature, $\mathrm{p}_{\mathrm{s}}$ the saturation vapor pressure over the pores of the sorbents, and $p_{\mathrm{x}}$ the partial vapor pressure of the adsorptive

$$
\Delta \mathrm{F}=-\mathrm{R} \cdot \mathrm{T}_{\mathrm{sorb}} \cdot \ln \left(\frac{\mathrm{p}_{\mathrm{s}}}{\mathrm{p}_{\mathrm{x}}}\right) .
$$


The approximation presented in Equation (5) was utilized to fit the experimental results and point out the regularities of the investigated material groups. Equation (5) is an analytical approximation and presents the relation between adsorbed water $\mathrm{W}$ and the Gibbs energy $\Delta \mathrm{F}$, wherein $\mathrm{W}_{0}$ is defined as the maximum amount of water, which can be adsorbed by the material (saturation water uptake). The order of data distribution $\mathrm{n}$ and the affinity between adsorbent and adsorptive is described by characteristic adsorption energy $\mathrm{E}$ :

$$
\mathrm{W}=\mathrm{W}_{0} \cdot e^{-\left(\frac{\Delta \mathrm{F}}{\mathrm{E}}\right)^{\mathrm{n}}} \text {. }
$$

The experiments were conducted using a thermogravimetric apparatus to weigh the sample's water uptake while the temperature was controlled and varied between 30 $200^{\circ} \mathrm{C}$, which corresponds to the Gibbs energy span of 20 $2000 \mathrm{~J} / \mathrm{g}$

\section{RESULTS AND DISCUSSION}

The results are categorized into three main sections due to the insights gained in procedural, material, and binder properties. The notation describing the sample composition in the current work follows the scheme: [binder-type][bindercontent]-[salt-content]. Clinoptilolite is always used as a host structure, if not specifically noted otherwise.

- Example: PS3-40 is a 3 wt.\% sulfate cement mixture with 40 wt.\% salt content (and 57 wt.\% clinoptilolite).

\section{A. Granulation procedure}

The process of granulation was governed by previous preparation steps such as milling and mixing. The latter one, including the initial water addition, was found to be the most crucial step and was thoroughly investigated. Figure 4 sums up some granulation results and the role of water as a key factor in the procedure. As reference material, 4A zeolite powder was granulated with Portland cement. Based on the water amount added during the mixing and agglomeration process, granules with different forms, size distribution, and stability, were produced. Depending on the hydrothermal properties of the initial raw materials, the water amount, mixing sequence, and duration were optimized. The initial materials adsorb/absorb water depending on ambient conditions and mixing duration. Porous host material and binder were treated with water before adding the hygroscopic salt-mixtures.

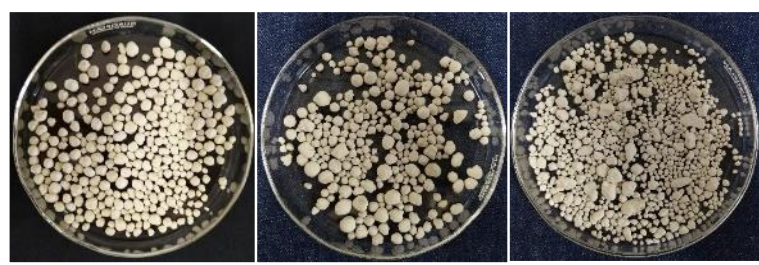

Figure 4 Influence of water amount during granulation of reference material 4A zeolite powder and PC. Left: well-formed and stable, middle: broad distribution of size and stability- an insufficient amount of water was added during the mixing process, right: small agglomerates and big chunksan insufficient amount of water added during mixing and compensated with overhydrating during the granulation process

The granulation procedures were systematically tailored and optimized for a broad range of material mixes. It was found to be a simple, low-cost, and satisfactory production approach for the thermochemical composite materials.

\section{B. Attapulgite bonded granules}

The initial compounds were successfully granulated in an industrial granulation site during under high ambient partial pressure and temperature, which coerced fast processing, as the salt-hydrates were absorbing ambient vapor quickly. The granules were dried in an oven at $110^{\circ} \mathrm{C}$. The granulation process was positively affected by the excellent binding properties of the attapulgite. The main issues appeared during the calcination as the high temperatures appropriate for sintering the binder were found to be too aggressive upon the salt-hydrates. Calcination parameters i.e. temperature, duration, and heating rate were varied to specify the problematic spans and to establish a treatment routine. The duration of calcination was 0.5-3.0 hours and sufficient mechanical effects were found for samples treated between 0.5 and 2.0 hours. A further strengthening effect was not determinable for increased treatment duration. The granules calcined at low temperatures $\left(350^{\circ} \mathrm{C}\right)$ showed hardly any stability upon humidity and crumbled visibly moist as the salts hydrated after hours in ambient conditions as presented in Figure 5 on the left side. Neither binder nor the zeolite was provided with enough energy to activate and build a strong framework for housing salt-hydrates. As the investigations showed no mechanical stability improvements at moderate calcination temperatures $450-550^{\circ} \mathrm{C}$, suggested sintering was implemented. The granules calcined at $750^{\circ} \mathrm{C}$ were found to display comparably a rigid and strong porous structure, which was insensitive to humidity even after days in ambient conditions as shown on the right side in Figure 5.

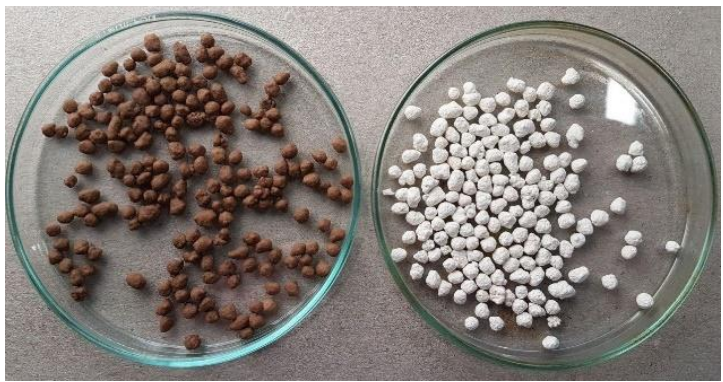

Figure 5 Attapulgite bound granules after $24 \mathrm{~h}$ in ambient conditions. Left: granules calcined at $350^{\circ} \mathrm{C}$ - granules are moist and crumble. Right: granules calcined at $750^{\circ} \mathrm{C}$ - rigid porous granules (sintering effect) arise, accompanied by salt leakage during the thermal procedure.

Stability measurements in form of break resistance were carried out gradually on attapulgite bonded composites. The efforts yielded in unsatisfactory results averaging around an applied force of $10 \mathrm{~N}$ at which the granules first crack. Granules calcined at high temperatures resulted in a porous network, however barely containing salt-amounts. The leaked salt from the granules also visibly damaged the glass dish, in which the samples were placed in the oven. Consequently, the activation of attapulgite and/or clinoptilolite only occurred at high temperatures, which was too aggressive upon the hydrothermal properties of salt-hydrates. Hydrothermal dissociation of the salts occurred during the thermal treatment and $\mathrm{HCl}$ was formed.

\section{Cement bonded granules}

First granules bonded with Portland cement were produced with an amount of $20 \mathrm{wt} . \%$ salt and $5 \mathrm{wt} . \%$ cement, hosted by clinoptilolite (PC5-20). To prevent the salts from overhydrating which would form acidic solutions and hinder 
the curing process, the granules were placed in an oven at $60^{\circ} \mathrm{C}$ after processing. After a curing time of 4 weeks in closed containers, the stability of the granules was tested yielding decent results (3-5 times higher than attapulgite samples). The stability results inspired further systemic investigations. Pressing questions regarding operational limitations, compatibility and essential material quantities of cementitious binders had to be clarified.

Various granule compositions were produced in a laboratory-scale with three cementitious binder mixtures and increasing salt concentrations. Special efforts were invested in intensive mixing procedure to avoid inhomogeneous binder hardening and salt distribution, which otherwise lead to varying structural quality and stability of the granules. However, despite the high standard deviation of the break resistance measurements, certain conclusions could be drawn. Stability measurements were conducted on reference $4 \mathrm{~A}$ zeolite $^{4}$ and based on the results a desirable break resistance threshold was stated at $35 \mathrm{~N}$ as a benchmark for the stability of granular composites. Zeolite samples were placed in an ambient environment (i.e. temperature and partial pressure) for several hours. Each newly produced composite was then tested in a corresponding stable state. Further relative humidity and temperature influences were cleared after placing the samples in fixed partial pressure tempered conditions. Resuming the vast evaluations, the combination of salt-hydrate granules with cementitious binders delivered adequate mechanical stability (break resistance) for partial pressures around 7.7 mbar and temperatures higher than and equal to $40^{\circ} \mathrm{C}$. A temperature decrease of less than $40^{\circ} \mathrm{C}$ was found to have destructive effects upon the granules as $\mathrm{CaCl}_{2}$ starts hydrolysis (acidic), reacts with the cement binder, and as a consequence deteriorates the stability. However, $40^{\circ} \mathrm{C}$ or higher is a common reactor temperature for the adsorption process in TES for domestic heating applications and can be set as a lower adsorption limit of the reactor to control the process.

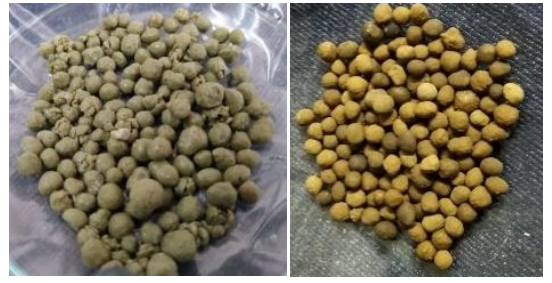

Figure 6 Clinoptilolite and salt-hydrate granules with Portland cement Left: moist and crumbling granules - conditioned at $35^{\circ} \mathrm{C}$ and high partial pressure $20 \mathrm{mbar}$ ( $55 \mathrm{mbar}$ saturation pressure) $\sim 0.3 \mathrm{~cm}^{3} / \mathrm{g}$ water uptake. Right: stable granules $-40^{\circ} \mathrm{C}$ and ambient partial pressure.

The evaluations of adsorption/hydration characteristics of the granules were conducted mainly within the application requirements, which are indicated in all following diagrams by the gray marked area of Gibbs energy between 350$1500 \mathrm{~J} / \mathrm{g}\left(\sim 40^{\circ} \mathrm{C}, 6 \mathrm{mbar}-180^{\circ} \mathrm{C}, 8 \mathrm{mbar}\right)$. The lower limit characterizes adsorption reaction, while the upper limit displays desorption (i.e. with solar thermal installations). The characteristic curves presented in Figure 7 demonstrate the hydrothermal adsorption properties of well-studied synthetic zeolites and act as a reference for newly developed composite

\footnotetext{
${ }^{4}$ 4A binder-free: Chemiewerk Bad Köstritz, Germany.

${ }^{5} 13 \mathrm{X}$ and 4A binder-free: Chemiewerk Bad Köstritz, Germany.
}

materials. The purple data points $(+)$ represent $13 \mathrm{X}$ and green data points $4 \mathrm{~A}(\mathrm{x})$ zeolites ${ }^{5}$. The black $(\rightarrow)$ markers are the results from measurements on $\mathrm{CaCl}_{2}$ anhydrate in granular form $^{6}$. Starting with the high Gibbs energy region, the water uptake increases and flattens between $750-900 \mathrm{~J} / \mathrm{g}$, which is promptly followed by a steep rise of the curve. The step in the course of water uptake can be interpreted as a hydration step of the $\mathrm{CaCl}_{2}$-salt. The resulting data for Gibbs energies below $500 \mathrm{~J} / \mathrm{g}$ indicates another step-like process or a saturation behavior of the salt. It is also important to address the dense granular form of $\mathrm{CaCl}_{2}$ samples. Despite the favorable surface area to volume ratio of spherical granules, the flattening curve in the lower Gibbs region could have been caused by the over-hydration of granule surfaces preventing (clogging) further water vapor passage to the center of the granules. These assumptions and interpretations are yet to be validated on multiple sets and forms of the used salt-hydrates. Consequently, calcium chloride displays excellent absorption properties in the gray marked energy region and has the potential to substitute synthetic zeolites as a low-cost and energy alternative.

The impact of the binder content on the adsorption/hydration properties of the composite granules was evaluated and is presented in Figure 8. Composites containing $40 \mathrm{wt} \%$ salt and increasing PS-content were selected, where all the characteristic curves follow the hydration step and steep slope trend of pure $\mathrm{CaCl}_{2}$ sample. The impact on the cement content was observed in the middle Gibbs region 750-1250 J/g, where large discrepancies between $3 \mathrm{wt} . \%$ and 10-15 wt.\% samples were detected. On the other hand, no distinct, qualitative difference could be observed for a cement content of $10 \mathrm{wt} . \%$ and $15 \mathrm{wt} . \%$, respectively. This fact can be caused by the inhomogeneity in the production procedure, as well as the stochastics of selected granule batch. In conclusion, the losses in water uptake, caused by binder content, still need to be optimized to fulfill the application requirements.

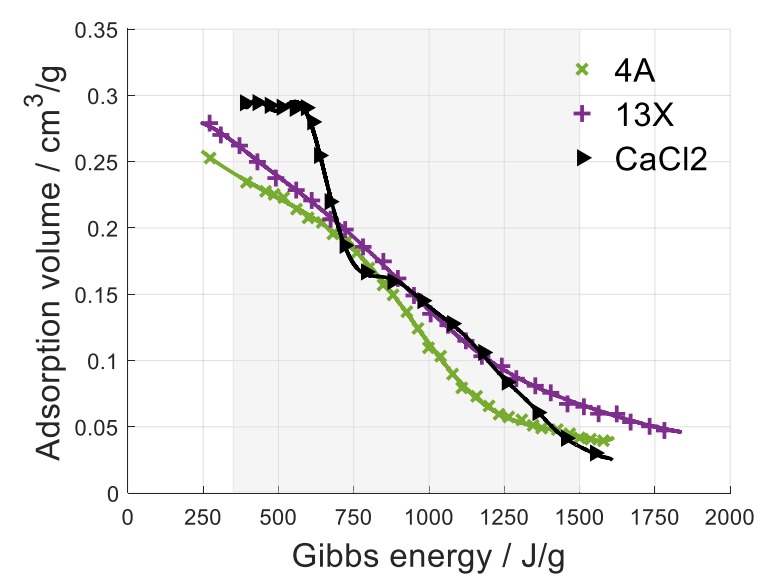

Figure 7 Characteristic curves of 4A binder-free ( $\mathrm{x}$ green), $13 \mathrm{X}$ binderfree (+ purple), and $\mathrm{CaCl}_{2}$-anhydrate in granules ( $\$$ black).

Further evaluations were conducted to quantify the impact of the salt content on the hydrothermal qualities of the composites. The results are depicted in Figure 9, where samples with a salt content of $20 \mathrm{wt} . \%, 40 \mathrm{wt} . \%$, and pure 
$\mathrm{CaCl}_{2}$ are compared. A characteristic step is visible in the case of the PS3-40 sample in the region of $750 \mathrm{~J} / \mathrm{g}$ and vanishes/is not detectable for the PS5-20 sample. Despite the latter fact, PS5-20 gains on water uptake in the lower Gibbs region below $500 \mathrm{~J} / \mathrm{g}$, which is a distinct characteristic of salthydrates in the composites. The adsorption at higher Gibbs energies (1000-1750 J/g) displays a flat slope governed by the host/clinoptilolite component due to its high amount (75 wt.\%) in PS5-20 composites. The results demonstrated that the potential of composites rises with the salt-content. According to lab-scale productions and investigations, a salt $\left(\mathrm{CaCl}_{2}\right.$ and $\mathrm{LiCl}$ mix $)$ content of up to $40 \mathrm{wt} . \%$ of the initial mass was considered as manageable in ambient mixing and granulation processes.

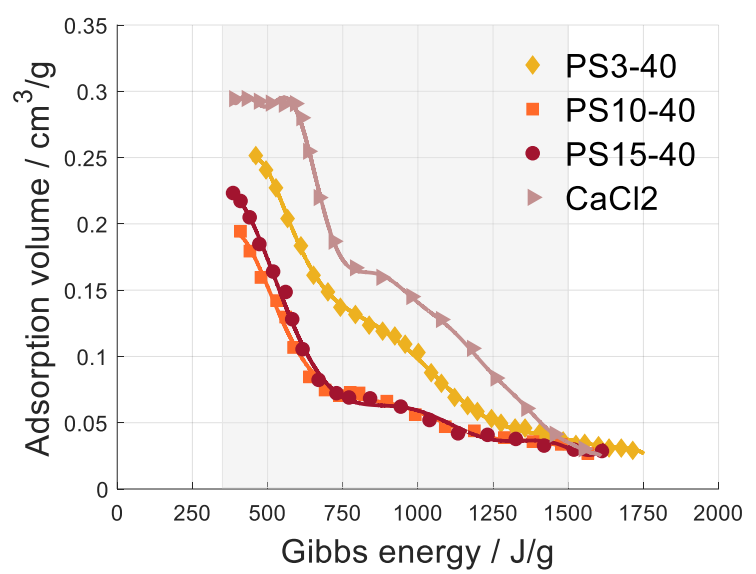

Figure 8 Characteristic curves of composite samples with clinoptilolite, salt-hydrate $40 \mathrm{wt} . \%$, and increasing cement content: 3 ( yellow), 10 ( orange), and 15 wt. $\%(\bullet$ red) and $\mathrm{CaCl} 2(\bullet$ pink $)$.

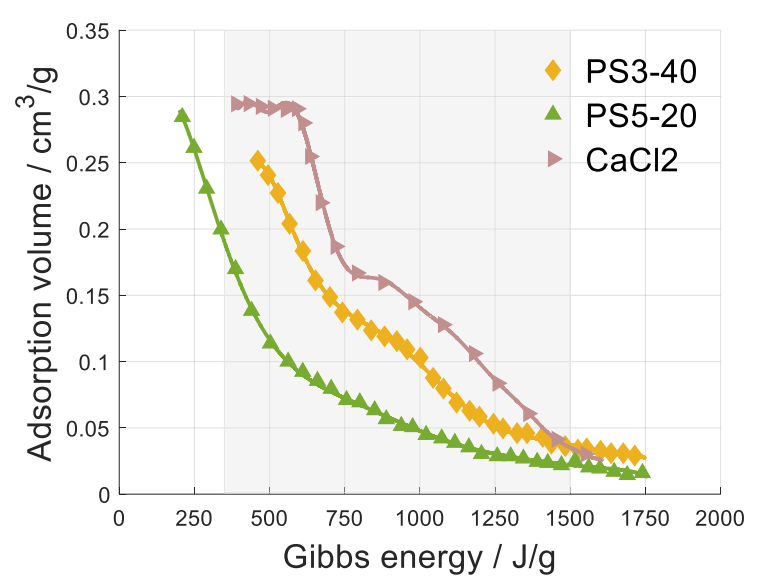

Figure 9 Characteristic curves of composite samples with clinoptilolite, similar cement content 3 ( yellow) and 5 wt.\% ( $\boldsymbol{\Delta}$ green) and increasing salt-hydrate amount 20 ( yellow) and 40 wt.\% ( $\boldsymbol{\Delta}$ green) and pure $\mathrm{CaCl}_{2}$ ( $>$ pink).

Multiple samples with comparable qualities were plotted side by side to ensure the reproducibility of the production and measurement routines. Two of those graphs are presented in Figure 10 and Figure 11, where the binder and salt content of the composites is equal in each case, whereas the binder type is varied. Figure 10 displays composites with a low binder amount of $5 \mathrm{wt} . \%$ and Figure 11 those with a high binder content of $15 \mathrm{wt} . \%$. In any case, no particular influence of the binder composition on the hydrothermal behavior of the composites was registered. Each graph illustrates nearly overlapping results for different binder types. Therefore, it can be concluded, that hydraulic cementitious binders can be further tailored and optimized for stability purposes.

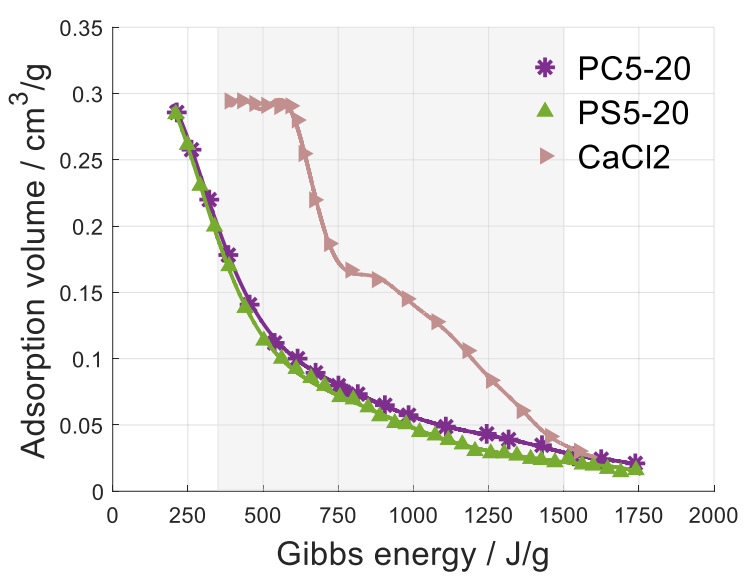

Figure 10 Characteristic curves of composite samples of equal cement and salt-hydrate content, yet different cement type: PC5-20 (- purple), PS520 ( $\Delta$ green), and $\mathrm{CaCl} 2(\boldsymbol{\nabla}$ pink)

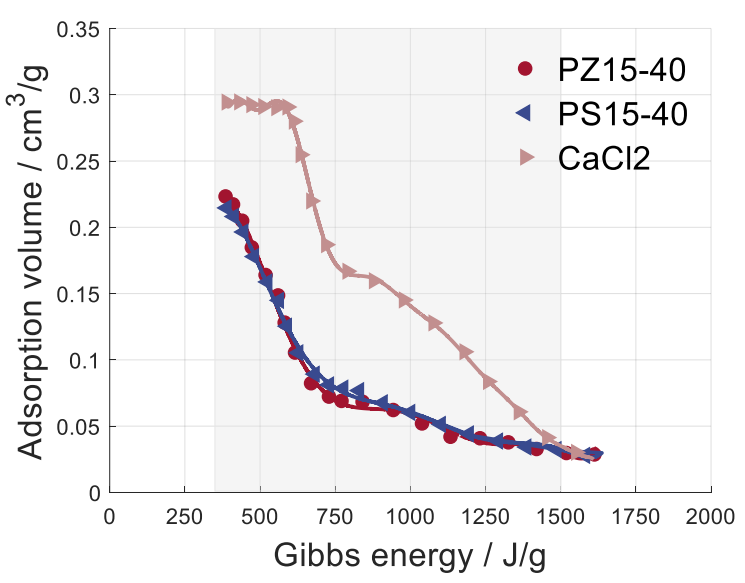

Figure 11 Characteristic curves of composite samples of equal cement and salt-hydrate content, yet different cement type: PZ15-40 ( $\bullet$ red), PS1540 ( $\$ blue $)$, and $\mathrm{CaCl}_{2}(\downarrow$ pink $)$.

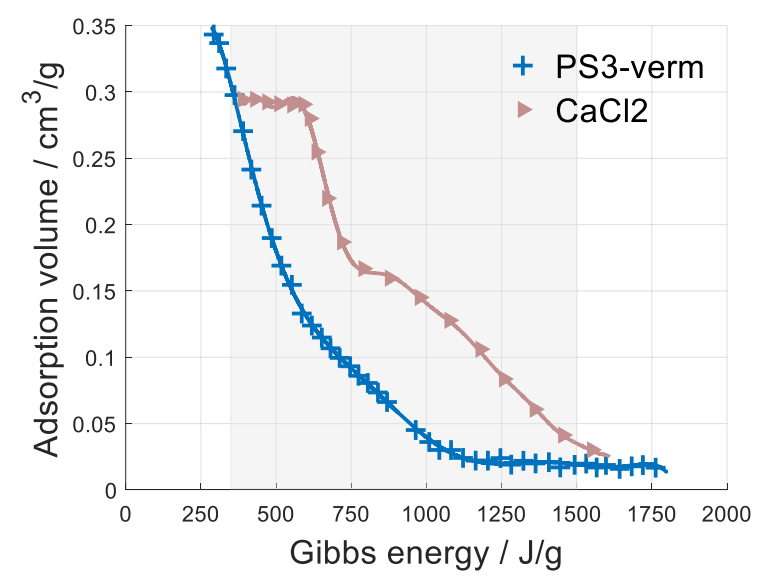

Figure 12 Characteristic curve comparison of pure $\mathrm{CaCl}_{2}$ granules ( pink) and $\mathrm{CaCl}_{2}$ impregnated vermiculite and granulated with sulfate cement mix (+ blue). 
The last Figure of this work presents common porous vermiculite hosting salt-hydrates by the impregnation method. The impregnated mass was also granulated in a disc with 3 wt.\% PS cement. After mechanical stability measurements of the vermiculite granules delivered adequate results, adsorption/hydration qualities were investigated. The characteristic curves describing those qualities are displayed in Figure 12. The data points recorded in the higher Gibbs region over $1100 \mathrm{~J} / \mathrm{g}$ show marginal water uptake, which once again indicates the weak adsorption characteristics of the host vermiculite. The energy range below $1100 \mathrm{~J} / \mathrm{g}$ is in agreement with previously discussed composite results, where hydration of the salts becomes more dominant in the lower Gibbs range.

\section{CONCLUSION}

The main focus of this work was to investigate suitable binder material and to determine their processing parameters. The granulation process was found to be highly adaptable and simply optimized for thermochemical materials. Two classes of binders (clay and cement) were studied based on binding mechanisms. The following conclusions were established for mineral attapulgite bound composites:

- Granules calcined at low temperatures were not stable and crumbled upon humidity.

- Granules calcined at high temperatures exhibited leakage of the salt; only the calcined framework remained, which was quite stable upon humidity, yet still lacking the required overall mechanical stability.

- Despite the variation of heating rate and removal of humid air during calcination, $\mathrm{HCl}$ formation could not be avoided.

- The calcination procedure does not align with the utilization of salt-hydrates characteristics.

The gained insights regarding investigations of hydraulic cementitious binders can be concluded as follows:

- The mechanical stability of the cement bound granules is comparable with synthetic zeolite granules.

- The stability decreases with higher partial pressure (\% RH) and lower temperature. Hydrolysis of salts damages the binder (acidic reaction). The lower applicable stability boundary was found to be around $7.7 \mathrm{mbar}$ at $40^{\circ} \mathrm{C}$.

- Adsorption/hydration of composites could be characterized and conclusions regarding salt and binder amount were drawn. The highest applicable salt amount was found to be $40 \mathrm{wt} . \%$ and the cement amount of $15 \mathrm{wt} . \%$.

- Foreseeable developments of the hydration process, such as hydration step and behavior in different Gibbs energy regions, of the salt-host composites were identified and discussed.

This work showed the potential of effectively produced, low-cost, and energy demand composites for thermochemical seasonal energy storage applications to substitute synthetic zeolites. However, further investigations are conducted to replace energy-intensive cement with eco-friendly alternatives. The mechanical stability and production parameters are being optimized to meet higher standards. As for further mechanical stability measurements, attrition needs to be considered.

\section{ACKNOWLEDGMENT}

The authors gratefully acknowledge the financial support for project New-TCM (Wi-2018-97351-/9-RA) by the EUEuropean Regional Development Fund (ERDF) and Federal Province of Upper Austria- Investments in Growth and Jobs (IGJ).

\section{REFERENCES}

[1] J. Lizana, R. Chacartegui, A. Barrios-Padura and C. Ortiz, "Advanced low-carbon energy measures based on thermal energy storage in buildings: A review," Renew. Sust. Energ. Rev., vol. 82, pp. 37053749, Feb. 2018.

[2] L. Scapino, H. A. Zondag, J. V. Bael, J. Diriken and C.C. M. Rindt, "Sorption heat storage for long-term low-temperature applications: A review on the advancements at material and prototype scale," Appl. Energ., vol. 190, pp. 920-948, Mar. 2017.

[3] P. A. J. Donkers, L. C. Sögütoglu, H. P. Huinink, H. R. Fischer and O. C. G. Adan, "A review of salt hydrates for seasonal heat storage in domestic applications," Appl. Energ., vol. 199, pp. 45-68, Aug. 2017.

[4] K. E. N'Tsoukpoe, T. Schmidt, H. U. Rammelberg, B. A. Watts and W. K. L. Ruck, "A systematic multi-step screening of numerous salt hydrates for low temperature thermochemical energy storage," Appl. Energ., vol. 124, pp. 1-16, Jul. 2014.

[5] M. Richter, E. M. Habermann, E. Siebecke and M. Linder, "A systematic screening of salt hydrates as materials for a thermochemical heat transformer," Thermochim. Acta, vol. 659, pp. 136-150, Jan. 2018 .

[6] S. K. Henninger, F. Jeremias, H. Kummer and C. Janiak - "MOFs for use in adsorption heat pump processes," Eur. J. Inorg. Chem., vol. 2012, no. 16, pp. 2625-2634, Dec. 2012

[7] S. K. Henninger et al., "New materials for adsorption heat transformation and storage," Renew. Energ., vol. 110, pp. 59-68, Sep. 2017.

[8] J. Jänchen, D. Ackermann, E. Weiler, H. Stach and W. Brösicke, "Calorimetric investigation on zeolites, AlPO4's and $\mathrm{CaCl} 2$ impregnated attapulgite for thermochemical storage of heat," Thermochim. Acta, vol. 434, no. 1-2, pp. 37-41, Aug. 2005.

[9] L. G. Gordeeva, A. Freni, Y. I. Aristov and G. Restuccia, "Composite sorbent of methanol 'lithium chloride in mesoporous silica gel' for adsorption cooling machines: performance and stability evaluation," Ind. Eng. Chem. Res., vol. 48, no. 13, pp. 6197-6202, May 2009.

[10] M. Tatlier, G. Munz and S. K. Henninger, "Relation of water adsorption capacities of zeolites with their structural properties," Micropor. Mesopor. Mat., vol. 264, pp. 70-75, Jul. 2018.

[11] A. Ristić, F. Fischer, A. Hauer, and N. Z. Logar, "Improved performance of binder-free zeolite $\mathrm{Y}$ for low-temperature sorption heat storage,” J. Mater. Chem., vol. 6, pp. 11521-11530, May 2018.

[12] L. Scapino, H. A. Zondag, J. V. Bael, J. Diriken and C.C.M. Rindt, "Energy density and storage capacity cost comparison of conceptual solid and liquid sorption seasonal heat storage systems for lowtemperature space heating," Renew. Sust. Energ. Rev., vol. 76, pp. 1314-1331, Sep. 2017.

[13] C. Ferchaud, "Experimental study of salt hydrates for thermochemical seasonal heat storage," Technische Universiteit Eindhoven, 2016.

[14] A. Jabbari-Hichri, S. Bennici and A. Auroux, "CaCl2-containing composites as thermochemical heat storage materials," So. Energ. Mat. Sol. C., vol 172, pp. 177-185, Dec. 2017.

[15] S. P. Casey, D. Aydin, J. Elvins and S. Riffat, "Salt impregnated desiccant matrices for 'open'thermochemical energy conversion and storage-Improving energy density utilisation through hygrodynamic \& thermodynamic reactor design". Energ. Convers. Manage., vol. 142, pp. 426-440, Jun. 2017.

[16] A. Ristić and N. Zabukovec Loger, "New Composite Water Sorbents CaCl2-PHTS for Low-Temperature Sorption Heat Storage: Determination of Structural Properties," Nanomaterials, vol. 9, no. 1, 27, Dec. 2019.

[17] M. Gaeini, A. L. Rouws, J. W. O. Salari, H. Zondag and C.C.M. Rindt, "Characterization of microencapsulated and impregnated porous host 
materials based on calcium chloride for thermochemical energy storage," Appl. Energ., vol. 212, pp. 1165-1177, Feb. 2018.

[18] B. Zettl, "Long-term thermochemical heat storage for low temperature applications, Proceedings of Solar World Concress SWC, 4.-7.11 2019 Santiago, CHILE".

[19] H. U. Rammelberg, T. Schmidt and W. Ruck, "Hydration and dehydration of salt hydrates and hydroxides for thermal energy storagekinetics and energy release," Enrgy. Proced., vol. 30, pp. 362-369, 2012.

[20] V.M. Van Essen et al. "Characterization of salt hydrates for compact seasonal thermochemical storage," In ASME 2009 3rd Internationa Conference on Energy Sustainability collocated with the Heat Transfer and InterPACK09 Conferences. American Society of Mechanical Engineers Digital Collection, pp. 825-830, 2009.

[21] R. Sutton, E. Jewell, J. Searle and J. Elvins, "Discharge performance of blended salt in matrix materials for low enthalpy thermochemical storage," Appl- Therm. Eng., vol. 145, pp. 483-493, Dec. 2018.

[22] X. J. Zhang, K. Sumathy, Y. J. Dai and R. Z. Wang, "Parametric study on the silica gel-calcium chloride composite desiccant rotary wheel employing fractal BET adsorption isotherm,” Int. J. Energ. Res., vol. 29 , no. 1 , pp. $37-51$, Dec. 2005

[23] T. Nonnen et al., "Erprobung eines thermochemischen Langzeitwärmespeichers auf Basis eines Zeolith/Salz-Komposits," Chem. Ing. Tech., vol. 88, pp. 363-371, Feb. 2016.

[24] G. Fraißler, M. Jöller, T. Brunner and I. Obernberger, "Influence of dry and humid gaseous atmosphere on the thermal decomposition of calcium chloride and its impact on the remove of heavy metals by chlorination,” Chem. Eng. Process: Process Intensification, vol. 48, no. 1, pp. 380-388, Jan. 2009

[25] L. G. Gordeeva and Y. I. Aristov, "Composites 'salt inside porous matrix' for adsorption heat transformation: a current state-of-the-art and new trends," Int. J. Low-Carbon Tec., vol. 7, no. 4, pp. 288-302, Jun. 2012.

[26] H. Liu, K. Nagano and J. Togawa, "A composite material made of mesoporous siliceous shale impregnated with lithium chloride for an open sorption thermal energy storage system," Sol. Energy, vol. 111, pp. 186-200, Jan. 2015

[27] A. Ertas, E. E. Anderson and I. Kiris, "Properties of a new liquid desiccant solution-lithium chloride and calcium chloride mixture," Sol. Energy, vol. 49, no. 3, pp. 205-212, Sep. 1992.

[28] J. Stark and B. Wicht, "Zement und Kalk: der Baustoff als Werkstoff," Springer-Verlag, 2013.

[29] K. Gleichmann, B. Unger, and A. Brandt, "Industrielle Herstellung von zeolithischen Molekularsieben," Chem-Ing-Tech, vol. 89, pp. 851862, May 2017.

[30] G. Cruciani, "Zeolites upon heating: Factors governing their thermal stability and structural changes," J. Phys. Chem. Solids, vol. 67, no. 910, pp. 1973-1994, Sep.-Oct. 2006.

[31] M. Johnson et al., "Cation exchange, dehydration, and calcination in clinoptilolite: In situ X-ray diffraction and computer modeling," J. Phys. Chem. B, vol. 107, no. 4, pp. 942-951, Jan. 2003.

[32] S. Chandrasekhar and P. Pramada, "Sintering behaviour of calcium exchanged low silica zeolites synthesized from kaolin," Ceram. Int., vol. 27, no. 1, pp. 105-114, 2001.

[33] M. R. Adam et al., "The adsorptive removal of chromium (VI) in aqueous solution by novel natural zeolite based hollow fibre ceramic membrane," J. Environ. Manage., vol. 224, pp. 252-262, Oct. 2018.

[34] W. Kuang, G. A. Facey and C. Detellier, "Dehydration and rehydration of palygorskite and the influence of water on the nanopores," Clay. Clay Miner., vol. 52, no. 5, pp. 635-642, Oct. 2004.

[35] A. R. Kamali, D. J. Fray and C. Schwandt, "Thermokinetic characteristics of lithium chloride," J. Therm. Anal. Calorim., vol. 104, no. 2, pp. 619-626, 2011.

[36] M. Dubinin, "The potential theory of adsorption of gases and vapors for adsorbents with energetically nonuniform surfaces," Chem. Rev., vol. 60 , no. 2 , pp. $235-241,1960$. 